\title{
Influence of Trainings on the Indicators of Sociopsychological Adaptation
}

\author{
Akhmetzyanova Nataliya Viktorovna ${ }^{1}$ \& Nugmanova Dzhamilia Renatovna ${ }^{1}$ \\ ${ }^{1}$ Kazan (Volga Region) Federal University, Republic of Tatarstan, Kazan, Russian Federation \\ Correspondence: Akhmetzyanova Nataliya Viktorovna, Kazan (Volga Region) Federal University, Republic of \\ Tatarstan, 420008, Kazan, Kremlyovskaya Street, 18, Russian Federation. E-mail: ah_anna@list.ru
}

Received: June 27, 2014 Accepted: September 25, 2014 Online Published: October 30, 2014

doi:10.5539/ass.v10n21p250 URL: http://dx.doi.org/10.5539/ass.v10n21p250

\begin{abstract}
The article deals with the singularities of influence of trainings on the processes of sociopsychological adaptation of students. The objective of the research is to study the singularities of influence of trainings on the change of the students' adaptation process indicators.

The authors suggest an original psychological express test in the form of interrogation. The indicators of sociopsychological adaptation were determined. The empirical study of changes of the adaptation processes indicators during the training was carried out, and the obtained results were analyzed. The fulfilled research gave reasons to conclude that the suggested hypothesis was valid, and that the training classes irregularly influence on the changes of students' adaptation indicators. The strongest influence of the classes affected the change of the emotional comfort indicator. The change of the indicator of safety feeling in a group was of nature that was more complex. It depends on the duration of the training classes. When the duration is short, the variation indicator decreases insignificantly, and the difference of the values before and after the trainings is not statistically valid. When carrying out the 4-day program, we observed statistically valid changes in the indicators, and the variation of changes in the indicators decreases more than six times (from $38.7 \%$ to $6.4 \%$ ).

Thus, the research showed high efficiency of the developed training program.

The obtained results allow developing more efficient psychological trainings targeting sociopsychological adaptation. At the development, it is necessary to take into account the complexity of dealing with the indicators of safety in a group and self-esteem.
\end{abstract}

Keywords: sociopsychological adaptation, adaptation training, adaptation indicators

\section{Introduction}

College age is an important stage of social and professional formation of personality. Deep changes in the social situation of development result in the identity crisis, which manifests itself in the person's expression of lack of confidence, discomfort, and perplexity. The main needs of this age are the needs in social and professional self-determination, sociopsychological support and protection, as well as the need in achievements (Ananyev, 1972).

During the first year of study, students simultaneously face various types of adaptation. The most important one to our opinion is the sociopsychological adaptation, because of which a student successfully assimilates the new environment of his activity, enters the system of different official and unofficial informal relations, adopts certain status in the new microenvironment, and asserts himself. Often, this process is accompanied by strong experiences and emotional discomfort (Kedrova, Nugmanova, \& Khairutdinova, 2009)

Based on this, it seems important to create for the first-year students positive emotional background, conditions for active daily living activities (for meeting the needs in intellectual, emotional, and moral development), friendly interactions between the students, as well as between students and the teachers' team since the very first days.

Is it possible to influence on this process and expedite it using specially developed psychological training programs? It is a known fact that trainings indeed influence on the processes of sociopsychological adaptation. But how do they influence and how efficient are they? 
Then, we face a problem: how do trainings influence on the change of adaptation indicators?

According to this problem, the object of the research is the influence of trainings on the process of sociopsychological adaptation of first-year students.

The hypothesis of the research resides in the assumption that trainings influence on the change of adaptation processes indicators irregularly.

The subject of the research covers the peculiarities of the influence of the change of the adaptation processes indicators of first-year students.

The objective of the research is to study the singularities of influence of trainings on the change of the students' adaptation process indicators.

The following tasks were solved during the research:

1. To develop an express methodology for evaluation of the adaptation indicators.

2. To develop the program of adaptation psychological trainings for first-year students

3. To reveal the changes of the adaptation processes indicators during the program.

4. To determine, the value of which indicators of the adaptation processes changes more.

In the research, we used the methods of analysis of scientific publications; the method of psychological express testing, during which we measured the changes of the adaptation indicators before the program and after it; the method of experiments; the method of statistical analysis of the obtained results.

\section{Methodology}

For studying the influence of the training classes on the indicators of sociopsychological adaptation of first-year students, we developed a test in the form of a questionnaire, the basis of which was the questionnaire suggested by Rogers and Dymond (Rogers \& Dymond, 1954).

R. Dymond determined the following versatile circumstances as the indicators of de-adaptation: low level of acceptance of other people; emotional discomfort, which can be versatile by its nature; dependence on other people; inspiration for dominance.

We modified and adapted the Roger \& Dymond's questionnaire and took into account that the important element necessary for adaptation in a society is self-respect (Osnitsky, 2004). As a result, we identified six indicators of sociopsychological adaptation - emotional comfort, feeling of safety in a group, self-respect, self-esteem (Ivchenko, 2007), respect to others, interest to others.

In order to let students understand the essence of each indicator and consciously evaluate their state and its change in the course of the training, we provided them with relevant explanations.

Literature sources offer various definitions of the indicators studied by us. The most relevant to our position views of scientists are those, which we took as the basis.

1. Emotional comfort is the state of confidence, calm, comfort, when a person is satisfied with everything, openly expresses his feelings, is optimistic and free from fear and anxiety. Emotional discomfort is the state experienced as not pleasant, burdensome, able to disturb normal common activity - anxiety, worriedness, fear, affectivetension, lack of self-confidence, excessive worriedness, suppressed state, and gloomy prognostications (Rogers \& Dymond, 1954).

2. Psychological safety in a group is a state of a human and appropriate situation, in which he is not afraid to show his real nature, behaves quite naturally and openly, is not afraid to be misunderstood or laughed at (Baeva, 2002).

3. Self-esteem is comparison of one's qualities and abilities, social standing, success, attractiveness, moral make-up with the qualities of other people. (Dictionary of psychological consulting (Godefroid, 1992).

4. Self-respect is respect (or disrespect) of a person to himself based on objective advantages and achievements of his personality, or, on the contrary, due to his fault or mistakes. The extent, to which a person esteems himself (Psychological dictionary, 2013).

5. Respect to another person is the attitude of one person to another, acknowledgement of his personal advantages (Kon, 2003). According to Kant, respect states the standard of human relations even more than fellow feeling. Only based on respect, mutual understanding can take place, which is required for adaptation. 
6. Interest to others is the general, interested, emotionally positive attitude of a person to people. We are interested in other people when they show interest to us. (Carnegie, 1936).

The responders were asked to estimate their state with each of the indicators on a 7-score scale (between 1 and 7 ). Students estimated their state twice: before the trainings and after them. The program of the training classes targeted creation of the atmosphere of trust and safety in the student group being formed, development of skills in constructive communication, learning cooperation and self-perception, understanding and acceptance of other people. The work involved two groups of first-year students of the Kazan Federal University: of the Institute of Philology and Art - 49 persons and of the Institute of Economics and Finance -49 persons. The total number of selected students was 98 persons.

The peculiarities of arrangement of the training classes were that for the first group, training lasted 2-3 hours during four subsequent days, and for the second group - also 2-3 hours, but only during two days.

For the first group, each day had its own objective.

The objective of the first day of the psychological program was to create safety and emotional comfort of staying in the group for each participant, reduction of the psychological distance between the group members. In order to achieve it, we included psychological exercises (Khryashcheva, 2004), which resulted in the change of the state of each member and formation of the group as a single unit. The objective of the second day was self-cognition and self-revelation, interest and formation of self-respect and respect to other members of the group. The exercises included in this day assumed self-revelation and obtaining information on other members of the group, as well as revealing interesting aspects of other members, finding common features with them, developing the skills of communicative competence (Sidorenko, 2008), the ability to listen up and understand other people. The objective of the third day was to improve group cohesion. To achieve it, the exercises of art therapy were introduced (Violet, 1989), the group image forming the feeling of belonging to the group (Shottenloher, 2001), the feeling of respect to oneself and to others. Role and Business games (Sukhovershina, Tikhomirnova \& Skoromnaya, 2006) allowed the members of a group to acquire experience of team cooperation and interaction, to achieve group objectives, to improve cohesion in the group, and develop the feeling of belonging to the group. The fourth day was oriented to development of leader's qualities (Evtikhov, 2007) and skills of constructive communication in the group, and also integrated the whole experience of the previous days.

There were less psychological trainings for the second group, but all the objectives of the four-day program were implemented.

\section{Results}

Following the results of the experimental research, a statistical analysis of the obtained data was carried out in order to find the change of indicators of the adaptation processes in both groups (Kornienko, 2000)

The second protocol was compiled using the results of the students' answers to the test questions, and average values of each indicator of adaptation before and after the training program for the first and second groups were calculated (refer to Figures 1, 2).

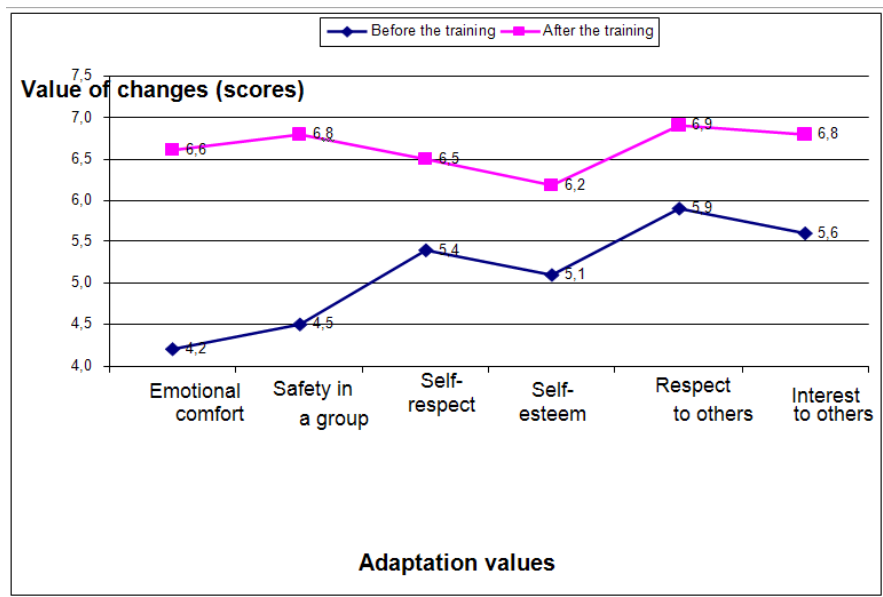

Figure 1. Diagram of the change of the adaptation processes indicators before and after the training classes in the first group 


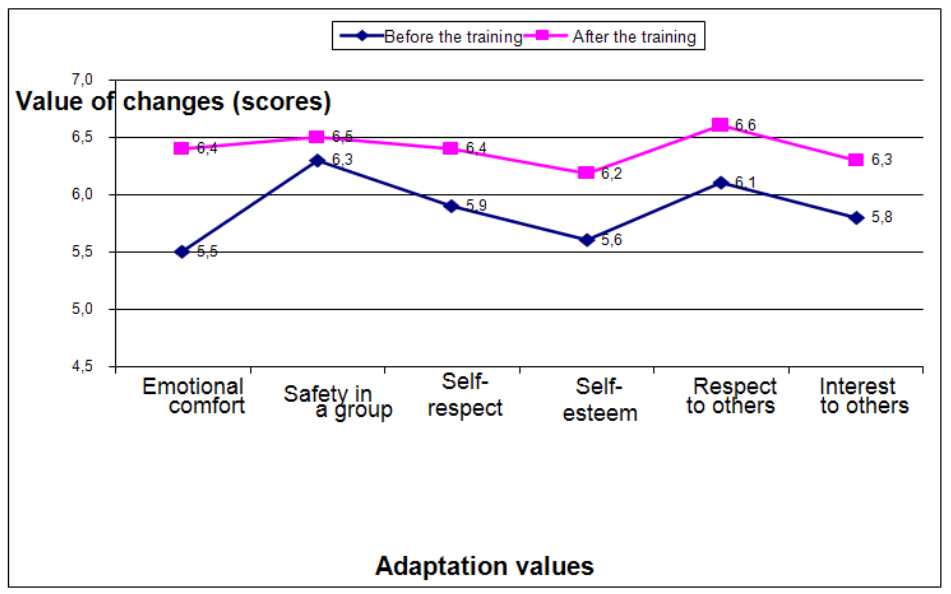

Figure 2. Diagram of the change of the adaptation processes indicators before and after the training classes in the second group

The results of the training program show changes of all determined indicators of adaptation. Changes of the indicator of emotional comfort are mainly observed in both groups ( 2.4 scores in the first group, and 0.9 scores in the second group). When comparing the changes of the adaptation indicators, we can clearly see that changes in all indicators in the first group considerably exceed the changes in the second group. These changes are especially notable with regard to the indicator of the feeling of safety in a group. In the first group, this change along with the change of the emotional comfort indicator is the strongest of all and equals to 2.3 scores. In the second group, the change of this indicator is on the contrary minimal and equals to 0.2 scores. The change of all indicators without a doubt points at the efficiency of the training classes and the influence of the trainings on the adaptation indicators. The most insignificant changes in the first group are observed in the 'respect to others' indicator (1 score), though before the training, this indicator had the highest value of all six indicators of adaptation.

The least value among all indicators of adaptation after the trainings in both groups was shown by the self-esteem indicator (6.2 scores in both groups).

To verify the validity of the changes, in the adaptation indicators before and after the trainings, we carried out statistical hypotheses verification by the Student's T-criterion separately for the two groups (refer to Table 1).

At the level of significance $\alpha=0.001$, for the degrees of freedom $\gamma=48$, the critical value of the Student's T-criterion is equal to 3.46 .

Table 1. Validity of the differences in states of two groups of students before and after the trainings

\begin{tabular}{ccc}
\hline \multirow{2}{*}{ Adaptation values } & \multicolumn{2}{c}{ Estimated Student's t-criterion } \\
\cline { 2 - 3 } & Group 1 & Group 2 \\
\hline Emotional comfort & 11.94 & $\mathbf{3 . 0 6}$ \\
Safety in a group & 9.07 & 6.29 \\
Self-respect & 7.54 & 6.11 \\
Self-esteem & 9.08 & 5.06 \\
Respect to others & 6.21 & 5.65 \\
Interest to others & 6.12 & \\
\hline
\end{tabular}

The obtained results indicate that in the first group, changes of all adaptation indicators are statistically valid. Only five of indicators in the second group were statistically valid. The change in the 'safety in a group' indicator is not statistically valid.

If we compare the estimated values of the Student's T-criterion in the first and second groups, we can see that the highest values are the values of all determined indicators of adaptation in the first group, i.e. where the training classes lasted four days. 
In order to see how the trainings influence on the adaptation indicators, we used the procedure of calculation of the adaptation indicators' variation ratios before and after the trainings in each group.

Following the results of the calculations, we built a table (Table 2).

Table 2. Variation of the changes in the adaptation indicators in the groups of tested persons before and after the trainings

\begin{tabular}{lcccc}
\hline \multirow{2}{*}{ Adaptation values } & \multicolumn{4}{c}{ Variation ratios (\%) } \\
\cline { 2 - 5 } & \multicolumn{2}{c}{ Group 1 } & Group 2 \\
\cline { 2 - 5 } & Before the training & After the training & Before the training & After the training \\
\hline Emotional comfort & 38.3 & 8.8 & 16.6 & 11.4 \\
Safety in a group & 38.7 & 6.4 & 15.6 & 13.4 \\
Self-respect & 21.7 & 9.4 & 14.7 & 13.5 \\
Self-esteem & 22.7 & 12.5 & 16.7 & 14.3 \\
Respect to others & 19.7 & 5.2 & 12.3 & 8.7 \\
Interest to others & 25.7 & 6.2 & 18.3 & 13.0 \\
\hline
\end{tabular}

The table shows that the variation value after the trainings decreases in both groups. Besides, the variation value change is strongly dependent on the duration of the training classes. While in the second group it decreases slightly for all of the indicators, the values of variation ratios of several indicators in the first group decrease several times. This indicates the fact that the groups become more homogeneous, and the longer the training program lasts, the more homogeneous they become.

If we compare the variation ratios in the groups before the trainings, we can see that they are considerably higher in the first group than in the second one for each indicator. And if we consider the variation ratios in the groups after the trainings, we can see a reverse situation: the variation ratios in the first group are lower than in the second group. It means that the first group has become more homogeneous, despite the fact that the original indicators had been more homogeneous in the second group. These are the results of the training program. The homogeneity indicators have become higher in the first group because a longer 4-day program of classes was offered to the students in the first group.

The least variation after trainings in both groups is observed for the 'respect to others' indicator (5.2\% and 8.7\%).

The highest variation is observed in both groups for the 'self-esteem' indicator (12.5\% and $14.3 \%)$. These results evidence that the changes in the 'respect to others' indicator are applicable to all students, and the changes in the 'self-esteem' indicator indicate different intensity for different students, which is probably determined by the nature of this indicator.

\section{Discussion}

The adaptation processes were considered in the publications by Rogers and Dymond (Rogers \& Dymond, 1954). A. K. Osnitsky continued their study (Osnitsky, 2004). Different indicators of the adaptation processes were determined in the publications by I.A. Baeva (Baeva, 2002), E.I. Ivchenko (Ivchenko, 2007). The importance of the feeling of belonging to a group and respect to others was mentioned by Dale Carnegie (Dale Carnegie, 1936), Bonnie M. Hagerty, Reg A. Williams, James C. Coyne and R. Margaret (Hagerty, Williams, Coyne, \& Margaret, 1996). All these studies were used as the basis for our research of the adaptation indicators and the possibility of influencing on them by training.

\section{Conclusion}

Following the results of the carried out research, we can conclude that the suggested hypothesis was confirmed and that the training classes irregularly influence on the changes of students' adaptation indicators. The strongest influence of these trainings concerned the change of the indicator of emotional comfort. The change of the safety feeling indicator in the group was of a more complex nature and depends on the duration of the training classes. At small duration of the classes ( 2 days), the variation ration decreased by $5.2 \%$, and the difference of indicators was insignificant. When carrying out the 4-day program, we observed statistically valid changes in the indicators, and the variation of changes in the indicators decreased more than six times (from $38.7 \%$ to $6.4 \%$ ).

Thus, the research showed high efficiency of the developed training program. 
The obtained results allow developing more efficient psychological trainings targeting sociopsychological adaptation. At the development, it is necessary to take into account the complexity of dealing with the safety in a group and self-esteem indicators.

\section{References}

Ananyev, B. G. (1972). Psychophysiology of the students' age and knowledge digestion. Vestnik VyssheyShkoly, 7, 17-26.

Baeva, I. А. (2002). The psychological safety in education. SaintPetersburg: Рос. гос. пед. ун-т им. А.И.Герцена. р. 44.

Carnegie, D. (1936). How to Win Friends and Influence People. Simon and Schuster (p. 291).

Dymond, R. (1954). Adjustement changes over Therapy Self - sorte. In R. Dymond (Ed.), Psychotherapy and Personality Changes (p. 429). Chicago: The University of Chicago Press.

Evtikhov, O. (2007). Training of leadership (p. 256). Saint Petersburg: Rech.

Godefroid, J. (1992). What is Psychology? (Vol. 1, p. 496). Moscow: Mir.

Hagerty, B. M., Williams, R. A., Coyne, J. C., \& Early, M. R. (1996). Sense of belonging and indicators of social and psychological functioning. Archives of Psychiatric Nursing, 10(4), 235-244.

Ivchenko, E. I. (2007). Formation of self-esteem as a factor of success at sociopsychological adaptation of students in the educational space of a higher educational institution (as exemplified by migrant students). thesis of Candidate in Psychology, Stavropol State University, Stavropol.

Kedrova, T. I., Nugmanova, D. R., \& Khairutdinova, M. R. (2009). Prospects of development of a psychological division at the TSHPU and its contribution to formation of personality of a teacher. Filologiyai Kultura.

Khryashcheva, N. Yu. (2004). Psychological Gymnastics in a Training (p. 265). Saint Petersburg: Rech.

Kon, I. S. (2003). A child and the society (The Higher Professional Education Series, p. 336). Moscow: Akademiya.

Kornienko, A. F. (2000). Theory and practice of psychological research: Study Guide (p. 258). Kazan: Kazan Pedagogical University.

Oaklander, V. (1989). Windows to our children: A Gestalt Therapy Approach to Children and Adolescents (p. 348). Gestalt Journal Press.

Osnitsky, A. K. (2004). Determination of the characteristics of social adaptation (pp. 43-56). PsikhologiyaiShkola.

Shottenloher, H. (2001). A drawing and an image in Gestalt Therapy (p. 256). Saint Petersburg: the Pirozhkov Publishing House.

Sidorenko, E. V. (2008). Training of communicative competence (p. 208). Saint Petersburg: Rech.

Sukhovershina, Yu., Tikhomirnova, E., \& Skoromnaya, Yu. (2006). Training of business (professional) communication (p. 128). Moscow: AkademicheskyProyekt.

\section{Copyrights}

Copyright for this article is retained by the author(s), with first publication rights granted to the journal.

This is an open-access article distributed under the terms and conditions of the Creative Commons Attribution license (http://creativecommons.org/licenses/by/3.0/). 